US scientists in new row over cancer at work

Previous studies of the incidence of cancer associated with occupational exposure to toxic substances may have seriously underestimated the true extent of the problem, according to a statement issued last week by three of the US National Institutes of Health.

Such studies had tended to estimate that the incidence of cancers which would be associated with occupational exposure was between 1 and 15 per cent. But they had been flawed by factors such as the failure to take into account the latency period of several decades that may occur between exposure and the appearance of a cancer. or the synergistic effect of exposure to several carcinogens. the statement claims.

Extrapolating from the results of recent studies of asbestos workers, it concludes that "there is nothing in the gross cancer statistics for the US population which is inconsistent with the hypothesis that up to 20-40 per cent of all cancers are (or will be in the next several decades) attributable to occupational factors".

Those who have contributed to the statement include Dr Arthur Upton, director of the National Cancer Institute, and Dr David Rall, director of the National Institute of Environmental Health Sciences, as well as

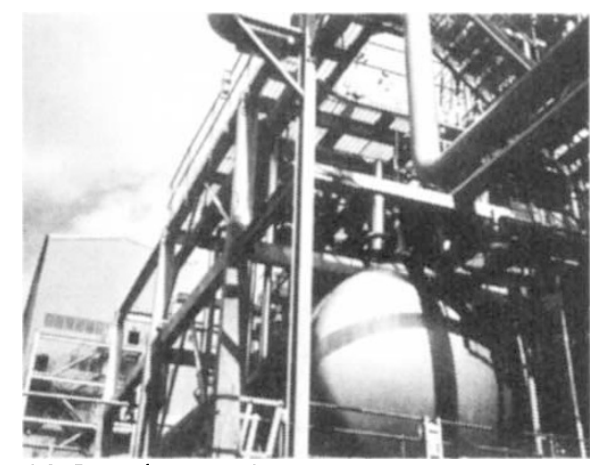

PVC production: dispute over hazards

eight other scientists from these two institutes and the National Institute for Occupational Safety and Health.

To offer a figure for comparing the risks from exposure to various industrial compounds, the statement chose "excess cancers" associated with each. (This quantity is defined as the product of the exposed population, the age-adjusted incidence of cancer and an adjusted risk ratio.) The number of annual excess cancers associated with asbestos is then 13,900 , but several other substances have excess numbers almost as high: arsenic, 7,300: benzene, 1,400; chromium, 7,900; nickel oxides, 7,300; and petroleum products, 9,100 .

The statement predicts that in the ycars ahead, cancers caused by exposure to other substances will also begin to rise sharply. "The five other agents together pose hazards similar to or greater than those posed by asbestos," says the report. "If only one of the thousands of chemicals introduced into commerce in the past 30

\section{Radio back-up in rural health service}

A VHF communication network is now operating in the rural area of Ballabhgarh, 35 kilometres south-east of Delhi. The project is an experiment to see whether such a system is an economic and effective way of providing health care for India.

The network was planned and set up by the Information, Planning and Analysis Group of the Electronics Commission for the All India Institute of Medical Sciences which is running a Comprehensive Rural Health Service Project at Ballabhgarh, providing health services to the local community and teaching medical and paramedical staff.

The VHF network consists of four 15-watt fully transistorised transceivers -three fixed ar.d one mobile- - and one 400-mW walkie-talkie set. The fixed transceivers are at Ballabhgarh Referral Hospital and two primary health centres and the mobile transceiver in a hospital van. The walkie-talkic set is provided to health workers during visits to patients in villages to communicate with the main hospital. The network covers 368.64 square kilometres and a population of 100,000 .

In India, where the majority of people live in villages, health centres are widespread with no telephone links between them. Information about both routine and emergency cases has to be delivered by hand and may often arrive too late to be of any use. A communication network between health centres is therefore seen as essential for effective health care in rural areas, and a VHF communication network is a novel move. The costeffectiveness has yet to be established. For this purpose, each call made or received from a station is recorded and medical case histories connected with each call pursued to find out the usefulness of the network in treating the patient. If the project proves its worth, its scope could be enlarged and the Ministry of Health and Family Welfare will be asked to establish similar networks in other areas.

Zaka Imam years proves to be as hazardous as asbestos, this could suffice to maintain comparable rates of occupationallyrelated cancer for decades into the future."

Several industry scientists refused to comment on the report until they had had several weeks to analyse the data. However the President of the Society of the Plastics Industry called the statement "an embarrassment to medical science". He cited a section of the report that predicted 1,940 excess cancer deaths a year to exposure to vinyl chloride as evidence of faulty methodology. "The facts show clearly that vinyl chloride is hazardous to man only at high levels of exposure and over relatively long periods of time", he .rid. The levels of population considered at risk by the statement are much too high, he concludes, saying that only 23 cases of cancer caused by exposure to vinyl cloride have been confirmed in the last 16 years.

The statement, which is based largely on a number of individual studies carried out by various of its authors, was used by Health Secretary Joseph A. Califano as the basis of a speech earlier this month to a national conference on occupational health organised by the American Federation of Labour-Confederation of Industrial Organisations (AFL-CIO).

In his speech, Dr Califano said that the results were "alarming", and that they would lead to an increased emphasis by the administration on the prevention rather than the cure of cancer.

John Douglas

\section{Scepticism over Soviet promise to let Levich go}

FrIENDS and colleagues of Veniamin Levich have greeted with guarded enthusiasm the news that he may shortly receive a visa to emigrate from the USSR to Israel. This is not the first time the 61-year old Academician has been promised an exit visa.

This time, however, the situation seems more auspicious. The announcement of a visa for Levich and his wife, as well as for 17 other families of Refusniks, was made by US Senator Edward Kennedy after his recent visit to Moscow, during which he had talks with Mr Brezhnev.

It seems likely that the current promises are designed to alleviate western reaction to the recent wave of "humanrights' trials in the Soviet Union. Senator Kennedy himself stressed that the granting of the promised visas would improve international relations. Until the Leviches actually arrive in the West, however, the possibility still remains that this promise is nothing more than a diplomatic gambit in the cause of paper detente.

Vera Rich 